\title{
Entre inseguridad y nomadismo: la maleta como símbolo y objeto de globalización
}

\author{
Between Insecurity and Nomadism: The Suitcase as Symbol and Object of Globalization \\ Entre insegurança e nomadismo: a mala como um símbolo e objeto da globalização
}

\section{Erica Durante}

UNIVERSITÉ CATHOLIQUE DE LOUVAIN, BÉLGICA

Profesora de la Université Catholique de Louvain, Bélgica. Doctorat en Littérature Générale et Comparée, Université Sorbonne Nouvelle, París III, Francia. Autora del libro Questions de poétique et d'écriture.

Dante au miroir de Valéry et de Borges (Honoré Champion, 2008) y editora de Los meridianos de la globalización. Ensayos sobre el tiempo en la literatura latinoamericana contemporánea, con un prefacio de Rodrigo Rey Rosa (Presses Universitaires de Louvain, 2015) y Le Double: littérature, arts, cinéma. Nouvelles aproches (Honoré Champion, 2015). Correo electrónico: erica.durante@uclouvain.be 


\section{Resumen}

La maleta es un objeto definitorio de la aeromovilidad contemporánea que remite simultáneamente a varios aspectos del mundo globalizado (conectividad, nomadismo, fluidez) y a sus derivas (factores de riesgo, exceso de seguridad). A partir de las tesis de Appadurai y Latour, se analiza este objeto mediante un corpus internacional de películas y textos literarios recientes (Benítez Reyes, Bradford, Fresán, Fuguet, Gamboa, Halfon, Fresán, Fuguet, Gamboa, Halfon Muñoz Molina, Neuman, Pamuk, Serrano Larraz, Tesich), considerando el valor ontológico, simbólico y poético de este "casi objeto" de nuestra cultura material.

Palabras clave: literatura contemporánea; cine; globalización; sociedad contemporánea; aeropuertos; viaje

\section{Abstract}

The suitcase is a defining object of contemporary aeromobility which refers simultaneously to several aspects of the globalized world (connectivity, nomadism, fluidity) and to their contradictions (risk factors, rigid security measures). Taking Appadurai's and Latour's theses as a starting point, we will analyse the role of the suitcase through an international corpus of films and recent literary texts (Benítez Reyes, Bradford,

Muñoz Molina, Neuman, Pamuk, Serrano Larraz, Tesich), symbolic and poetic value of this "almost-object" for our material culture.

Keywords: contemporary literature; cinema; globalization; contemporary society; airports; travel considering the ontological,

\section{Resumo}

A mala é um objeto definitório da aeromobilidade contemporânea que refere simultaneamente a vários aspectos do mundo globalizado (conectividade, nomadismo, fluidez) e suas derivas (fatores de risco, excesso de segurança). A partir das teses de Appadurai e Latour, analisa-se este objeto mediante um corpus internacional de filmes e textos literários recentes (Benítez Reyes, Bradford, Fresán, Fuguet, Gamboa, Halfon, Muñoz Molina, Neuman, Pamuk, Serrano Larraz, Tesich) considerando o valor ontológico, simbólico e poético deste "quase objeto" da nossa cultura material.

Palavras-chave: literatura contemporânea; cinema; globalização; sociedade contemporânea; aeroportos; viagem

\section{Cómo citar este artículo:}

Durante, Erica. "Entre inseguridad y nomadismo: la maleta como símbolo y objeto de globalización". Cuadernos de Literatura 20.40 (2016): 352368. http://dx.doi.org/10.11144/Javeriana.cl20-40.einm 


\section{La maleta como "puro objeto", "cosa en sí"}

La visión de una maleta nos expone de manera espontánea e inmediata a la evidencia de un objeto práctico y funcional que podemos denominar puro objeto (Latour, Nous n'avons, 79), cosa en sí (112), aun cuando se trata de algo ordinario y estándar que no tiene individualidad propia. ${ }^{1}$ Objeto del flujo, de la compresión espacio-temporal propia de nuestro mundo, la maleta es un objeto-símbolo por excelencia de aquella globalización económica tan criticada, sobre todo, por no tomar en cuenta los aspectos humanos del intercambio cultural.

Para ilustrar esta primera función que caracteriza a la valija como "puro objeto", según la denominación que proponemos aquí, consideremos para empezar un ejemplo proveniente del cine, que justamente muestra esta función meramente utilitaria y transitoria de la maleta. Hay una película, sobre todo, que plantea, de manera clara y constante, el estatuto pragmático y banal de la maleta. Se trata del filme de 2009 de Jason Reitman, adaptación de la novela homónima Up in the Air (de Walter Kirn), interpretada por George Clooney, quien encarna a Ryan Bingham, alto directivo de recursos humanos de una empresa norteamericana, cuya misión consiste en desplazarse y encontrarse con empleados de diversos lugares de Estados Unidos para anunciarles su despido inminente del puesto de trabajo. El recorrido diario de este personaje on the move incluye aeropuertos, aviones, hoteles y taxis; sin embargo, además del pasajero, solo admite un objeto, la maleta. Una maleta estándar de ejecutivo, tanto por su apariencia exterior - medidas autorizadas para equipaje de mano: $50 \times 40 \times 20$ centímetros, ruedas todoterreno, mango retráctil- como por su contenido - camisas, corbatas, bolsas de plástico transparentes para ropa interior y ropa sucia, fundas de trajes y de zapatos (Reitman $54^{\prime} 6^{\prime \prime}-5{ }^{\prime} 58^{\prime \prime}, 277^{\prime} 00 "-277^{\prime \prime} 10^{\prime \prime}$ )—. Otros objetos igualmente estándares, dado que podríamos encontrarlos, hasta casi colocados según la misma disposición, en cualquier maleta de cualquier ejecutivo itinerante (Faulconbridge).

De hecho, esta misma indumentaria es la que contiene la maleta del personaje Alejo de Historia argentina (Fresán), variante suramericana de Ryan Bingham. Igual de nómada, Alejo sube y baja de un avión llevando un equipaje idéntico, sea cual sea su destino, perfectamente funcional y exageradamente minimalista, $y$, sobre todo, "invariablemente impersonal" (163).

1 Las nociones mismas de puro objeto y de cosa en sí deben entenderse aquí en relación con las tesis de Bruno Latour sobre los casi objetos (Latour, Nous n'avons 73). Contrariamente a los híbridos definidos por el sociólogo francés, el "puro objeto" reenvía, en este caso, a un pensamiento del objeto como algo irremediablemente distinto del sujeto, perteneciente a una zona de no humanidad, radicalmente separada de lo humano. 
La profesión de Alejo lo obliga a moverse por el mundo con cierta asiduidad. Lo que equivale en su caso a perder valijas con cierta asiduidad. [...] Alejo ya es personaje conocido en los aeropuertos del mundo. "Ahí viene el argentino, ese que siempre pierde las valijas", piensa Luigi M. detrás de un mostrador del aeropuerto de Milán. Mr. Samsonite. Así fue, así es y así será. Por eso Alejo arma sus valijas con el mismo espíritu de una madre que envía a su hijo a la guerra. Adiós, hijo mío, Dios te ampare. Por eso las valijas de Alejo llevan invariablemente artículos impersonales, repetidos hasta el cansancio. El mismo traje verde botella, la misma corbata verde pastel. Nada personal [...]. (Fresán, Historia 163)

En consecuencia, el contenido mismo del equipaje es un dato determinante, por cuanto la sabiduría del pasajero experimentado se mide precisamente en función de la fluidez de su valija, en términos de repartición del contenido, ergonomía del diseño, ligereza y facilidad de transporte (Caplan 95-126). En este sentido, el poema del escritor norteamericano Timothy Bradford "Nomads with Samsonite" quizás contenga la lección más extrema del minimalismo y la fluidez a la cual tiene que tender el equipaje de un nómada contemporáneo, que utiliza las partes de su propio cuerpo como accesorios de viaje, para protegerse de la intemperie, orientarse en su desplazamiento e interactuar con los autóctonos:

Decorum dictates we pack light.

Bernoulli's principle

depends on it. So we'll take

your long hair, like a russet kaffyeh,

to keep us warm, and my long arms

to serve as sundial, compass, sign flags to the locals. (37)

Al faltar la fluidez, en cuanto condición primaria del viajero frecuente, nos encontramos ante una situación como la que presenta otra secuencia de la misma película $U p$ in the Air, en la cual la maleta de una novata de los viajes en avión, Natalie, interpretada por Anna Kendrick, representa, por contraste, una manera hoy obsoleta, si no ridícula, de desplazarse (Reitman $27^{\prime} 49^{\prime \prime}-28$ '50"). Su maleta no rueda bien, es lenta, incómoda, pesada, repleta de objetos inútiles (almohada cervical y almohada de cama) para un habitual de lo que Faulconbridge define como la aeromovilidad ejecutiva (376-377). 


\section{La maleta como objeto de riesgo}

Pese a ser un objeto-símbolo de la fluidez del mundo globalizado, la maleta, sin embargo, también puede conllevar tanto cierta perturbación del flujo como una desaceleración del viaje hasta su estancamiento. En este sentido, una de las razones más recurrentes de detención del pasajero consiste en las medidas y protocolos de seguridad, desde el check-in hasta los controles de aduana. El cálculo que hace el pasajero de Up in the Air para esquivar las filas con familias y personas mayores, al dirigirse hacia la cola de los emprendedores asiáticos (Reitman $\left.28^{\prime} 54^{\prime \prime}-29^{\prime} 41^{\prime \prime}\right)$, prueba hasta qué punto teme los atascos de equipaje debidos al exceso de las medidas de seguridad y la enorme pérdida de tiempo que estos pueden producir.

Otras ficciones recurren a estos mismos momentos de interrupción del flujo, aunque los traten de manera más positiva y útil para el desarrollo de la narración. Es, por ejemplo, el caso de la novela Aeropuertos (Fuguet), de 2010, en la cual un episodio banal produce la alteración del tránsito regular del equipaje. Álvaro y Pablo, los protagonistas, se detienen delante de un empleado que "envuelve en plástico transparente unas maletas" (Fuguet s. p.). Durante la escena, que los personajes contemplan desde la fila del check-in, nada acontece: "los bolsos giran alrededor de una suerte de dispensador de esa película transparente con el que tapan potes y postres y ollas". Pablo "escucha música de su celular" mientras Álvaro "revisa el pasaporte y los papeles notariales que le permitirán a un menor abandonar el país" (s. p.). El viaje queda entonces suspendido en esta fase en la que Álvaro "coloca la maleta sobre la pesa", esperando que la azafata de tierra le entregue la tarjeta de embarque, antes de empuñar "la pesada maleta y [colocarle] un sticker que dice FRA" (s. p.), código de identificación del aeropuerto de Fráncfort.

En el libro Cómo viajar sin ver (Neuman), de 2010, el mostrador de registro también funciona como un impedimento hacia el desenvolvimiento regular del tránsito. A pesar de que el pasajero, el mismo Neuman, en salida desde el aeropuerto de Guatemala hacia Estados Unidos solo lleve equipaje de mano, sufre un retraso. La empleada de American Airlines que lo recibe parece detectar algo raro, si no sospechoso, en su forma de traveling light, y termina sometiéndolo a un interrogatorio molesto para el pasajero, sobre todo considerando que Neuman, en transbordo desde hace ya varias semanas entre aeropuertos y aviones del continente americano, ha tomado precisamente la precaución de reducir su equipaje para no caer en la red de los controles de seguridad. Leemos en el relato del viajero:

Cuando ve que mi equipaje es de mano, la empleada me pregunta preocupada si llevo líquidos (sí llevo), cuáles exactamente (gel, champú, perfume), de cuántas onzas (¿ंcuánto es una onza?), si tengo bolsas ziploc bags (excuse 
me?), si me pasa algo o soy idiota (sí, soy), si estoy seguro de que no quiero despachar mi maleta (no, no quiero). La empleada me mira como se mira a un paracaidista novato, me entrega mi tarjeta de embarque, suspira profundamente. (Neuman, Cómo viajar 178)

Sobre todo después del 11 de septiembre de 2001, y en el contexto de la amenaza terrorista actual, el equipaje, sea cual sea su forma y tamaño, representa un objeto de riesgo, un peligro, frente al cual se han adoptado, a escala mundial, nuevos dispositivos de control y seguridad cada vez más coercitivos. Esta nueva percepción de la maleta como objeto sospechoso se ha vuelto común en nuestra manera de viajar y aparece en numerosas ficciones que relatan situaciones de desplazamiento en avión. Por razones obvias, desafortunadamente familiares para todos nosotros, los aeropuertos y los aviones son los lugares que más han sufrido y sufren el endurecimiento de las medidas de seguridad. La ficción literaria española y latinoamericana que, cada vez más, incluye estos dos lugares en sus tramas, también ha asimilado esta percepción pos-2001 alterada de la maleta $\mathrm{y}$, en general, de todo equipaje.

La maleta del personaje de Antonio Muñoz Molina en la novela Ventanas de Manhattan (2004), en principio, debería parecerse a la del personaje de Up in the Air y ser "puro objeto" de transición, útil para el transporte de lo mínimo indispensable durante el viaje. Sin embargo, a pesar de ser por definición un objeto nómada, prácticamente incorporado al individuo desde el momento en que se produce un desplazamiento en determinadas circunstancias, la maleta también puede convertirse en un objeto de demora del viaje. El primer capítulo de Ventanas de Manhattan relata precisamente la llegada del personaje principal al aeropuerto neoyorquino JFK, procedente de un vuelo interno. El hecho de que, como en el caso de Neuman, el personaje lleve consigo un equipaje, aunque sea de mano, es necesariamente fuente de una dilatación del viaje, debida a los controles repetidos que el personaje tiene que soportar en el recorrido que separa la puerta de desembarque del avión de la "fila de taxis amarillos al otro lado de las puertas de cristal" (28). Al transitar por este trayecto, la maleta se encuentra de hecho expuesta a varias obstrucciones y verificaciones, hasta ser subvertida tanto en su forma como en su contenido. Pasa entre las "manos enguantadas de plástico transparentes" (28) de varios vigilantes, que obligan al pasajero a abrirla para revisar su interior "en busca de las pruebas de [su] complicidad en algún genocidio o de los caracoles ilícitos que habrían viajado adheridos al interior de [sus] jerseys" (26). Estos gestos protocolarios, impuestos por las medidas de seguridad de las autoridades estadounidenses, revuelven el orden inicial del 
equipaje, establecido por el viajero, a veces con mucha precaución, si no arte - ya que se suele hablar del arte de hacer la maleta - y producen una doble alteración de esta. Por un lado, se presenta como objeto que transporta la intimidad del pasajero, aquí profanada por manos y ojos externos y, por otro, en cuanto objeto cuya función primaria e intuitiva - el tránsito- se encuentra subvertida por el "examen inquietante" y los "ademanes bruscos y expertos" de los aduaneros (2728). El estado de ánimo del personaje-pasajero en este caso depende de la maleta misma, que expone al viajero a sensaciones de preocupación y miedo:

Si me registran - piensa el protagonista - temo llevar algo prohibido en mi equipaje, si tengo miedo pongo cara sospechosa, si el aduanero de los guantes de plástico se me queda mirando descubrirá que estoy inquieto por algo y llevará a cabo un registro más exhaustivo. (28)

\section{La maleta como objeto de mediación}

Más allá de las medidas de seguridad, también existen otras circunstancias que remiten a la normalidad del tránsito aéreo internacional, pero que igualmente implican una contestación de la definición primaria de traslado que usualmente atribuimos a la maleta en cuanto "puro objeto", "cosa en sî". Por su obviedad y frecuencia, las situaciones de detenimiento relacionadas con el equipaje, a las cuales se encuentra confrontado el pasajero, se han vuelto un expediente habitual para la ficción, que precisamente utiliza estos paréntesis de inmovilidad como medio para que los personajes se relacionen entre sí. De esta manera, las interrupciones del tránsito de la maleta adquieren en la ficción un poder de mediación elevado, que hace que se establezcan vínculos, aunque sea provisionales, entre pasajeros, como conversaciones, encuentros o hasta reencuentros con personas singulares.

A menudo, la literatura y el cine latinoamericanos contemporáneos presentan escenas de contacto entre individuos que justamente se construyen alrededor de una maleta, la cual, de modo provisional, se encuentra en modalidad stand by. Entre los ejemplos disponibles citaremos el comienzo de Monasterio (Halfon), Los impostores (Gamboa) y el primer episodio de la reciente película argentina Relatos salvajes (Szifrón). Estos ejemplos presentan tres situaciones distintas por su configuración espacial dentro del avión o del aeropuerto y plantean tres usos posibles que la ficción hace de esta función alterada de la maleta.

La novela Monasterio, del guatemalteco Eduardo Halfon, empieza con la llegada del personaje principal, Eduardo, y de su hermano al aeropuerto de TelAviv. El aterrizaje coincide con el inicio de una espera larga y calurosa de la maleta alrededor de la cinta transportadora de equipaje, también llamada carrusel. En la 
"pastosa humedad" mediterránea (13) del Aeropuerto Internacional Ben Gurión, los carruseles permanecen inmóviles, mientras los pasajeros matan el tiempo de la espera, más de una hora, encendiendo cigarrillos y respetando religiosamente las medidas de seguridad extremas impuestas por las autoridades israelíes. En esta situación de estancamiento aparece de repente "un batallón de aeromozas de Lufthansa: [...] cinco o seis chicas todas vestidas con sus relucientes uniformes de Lufthansa y con sus gorritas amarillas de Lufthansa y sonriendo sus enormes sonrisas de Lufthansa" (16). Una vez más, alrededor del carrusel de maletas "que seguía crujiendo y rechinando" (18) es donde acontece el reencuentro entre Eduardo y Tamara, una antigua amante ahora envuelta en el uniforme amarillo de Lufthansa. Un reencuentro determinante para la continuación de la historia hasta su final. Quizás parezca bastante singular pero, además de destacar generalmente como topos de muchas ficciones contemporáneas, el carrusel también funciona como cronotopo del viaje en avión, dado que marca el momento de recuperación, por parte del pasajero, de aquel objeto, la maleta, que le permitirá acceder, con su propia identidad física y material, al lugar de destino, con el cual por primera vez se encuentra, geográfica, lingüística y temporalmente durante la espera en torno a la cinta de las maletas.

La novela Los impostores, de Santiago Gamboa, presenta una circunstancia similar a la de Monasterio, que tiene un efecto igualmente importante en el desarrollo de la historia. El carrusel número 14 del aeropuerto de Pequín escupe simultáneamente las maletas de tres aviones que acaban de llegar de tres lugares alejados del planeta: Los Ángeles, Fráncfort y Hong Kong. A causa de una rara coincidencia, los tres equipajes pertenecen respectivamente a tres de los personajes clave del relato, que están esperando, con sus carritos, ver desfilar sus maletas encima de la cinta negra para poder abandonar el aeropuerto y llegar finalmente al hotel. Este momento ordinario de la espera del equipaje por parte de los tres personajes reunidos fortuitamente por primera vez alrededor del carrusel cobra toda su importancia en la lógica global de la narración, dado que el resto de la novela los verá paradójicamente conectados en la búsqueda de un mismo manuscrito, perteneciente a una sociedad secreta, conservado en algún lugar recóndito de Pequín.

La película Relatos salvajes (2014), del director argentino Damián Szifrón, es el último ejemplo que elegiremos para ilustrar esta contestación de la función inicial de la maleta. "Pasternak", el primero de los seis cortos de esta comedia negra, acontece entre el mostrador de facturación y el despegue de un vuelo nacional de Aerolíneas Argentinas. El episodio comienza con el encuentro entre un hombre y una mujer y tiene como protagonista una maleta. El personaje masculino ayuda a una modelo que acaba de subir a la cabina del avión a guardar 
su maleta en el compartimento para equipaje. Este momento funciona como el primer contacto verbal y físico entre ambos personajes que, una vez sentados, seguirán charlando hasta descubrir, y hacer descubrir a los demás pasajeros, la extraña razón - el vínculo con Pasternak, el comisario de abordo- que hace que tanto ellos como todos los ocupantes del avión coincidan en ese mismo vuelo destinado a estrellarse. Este último ejemplo subraya, una vez más, la función de mediación de la maleta.

\section{La maleta como objeto del yo}

La función de mediación at large que acabamos de analizar nos lleva a considerar otro papel particular que tiene la maleta. En cuanto prolongación, durante el viaje, de la identidad física y material del individuo (Löfgren 443), la maleta tiene la función de mantener la conexión con lo local, punto de partida del viaje. Al desplazarse, el sujeto lleva una parte de su esfera interna consigo. El contenido de su equipaje, a pesar de ser relativamente estándar, está en realidad profundamente marcado por la identidad de cada individuo.

Según esta hipótesis, entendemos también mejor el miedo generalizado a perder el equipaje, dado que esa pérdida representa en el fondo un verdadero extravío de sí. Se entiende entonces mejor, desde esta óptica, la lectura dantesca que propone el novelista serboamericano Steve Tesich de una situación de extravío de equipaje:

Si Dante viviera hoy en día, pienso, habría hecho un círculo en el infierno que fuera una cinta transportadora de equipajes. Y en dicho círculo, mientras la cinta daba vueltas, las almas condenadas serían castigadas eternamente a esperar un equipaje que no llegaba nunca. $(373)^{2}$

La espera ad aeternum del equipaje es aquí asimilada a la atrocidad del contrappasso. Como en los peores episodios infernales, al cometer el pecado de entregar sus maletas al comienzo del viaje, los pasajeros se exponen no solamente a la pena material de no poder recuperarlas nunca más, sino, además, a la pena física y mental de la espera perpetua. Se podría decir que pasamos aquí de una fenomenología a una metafísica de la maleta, en la cual lo que cuenta ya no es la "cosa en sî", "puro objeto", sino las proyecciones y representaciones humanas que se encuentran reflejadas en ello.

2 Agradecemos a Vicente Luis Mora por habernos indicado tanto esta referencia como las relativas al poemario de Felipe Benítez Reyes, a la novela de Miguel Serrano Larraz y a la obra del artista plástico Eduardo Úrculo. 
Así, las maletas contemporáneas, si bien es cierto que se caracterizan por su fluent appearance, no dejan de ser un receptáculo, aunque sea provisional, de la identidad del individuo. Accesorio de moda y, desde Louis Vuitton en 1854, objeto imprescindible del traveling with style (Vuitton) y de la industria del lujo, la maleta, por un lado, corresponde a la lógica comercial implacable de las grandes marcas y, por otro, se adapta a las necesidades humanas no solamente más inmediatas, sino también más recónditas. Este anclaje en lo humano es particularmente visible en la siguiente consideración de un personaje de la novela Autopsia (2013) del español Miguel Serrano Larraz, que, al contemplar el color extravagante de su maleta, siente la urgencia de tener una segunda experiencia sensorial, táctil, con el objeto, una vez más, no tanto para relacionarse con el "puro objeto" - lo cual sería inquietante-, sino consigo mismo: "la maleta resplandece con un violeta eléctrico $[. .$.$] me gustaría abrirla y tocarla [. .$.$] pero sé que no lo voy a hacer,$ la golpeo con la punta del zapato para comprobar que es real, que existe (para comprobar que existo yo, que existe la realidad)" (41).

Esta contradicción entre el estatuto tan efímero como irreal del objeto maleta y la condición del individuo contemporáneo está bien presente en muchas otras obras y creaciones actuales. Varios son los autores que establecen un vínculo interesante entre la identidad del ser humano que posee la maleta y el objeto mismo, la "cosa en sî". En su conferencia "Writing with Two Passports", Andrés Neuman se refiere a aquellas marcas materiales de la identidad de cada persona que se acumulan en el equipaje, como la ropa sucia o los zapatos malolientes. Efectos y olores que, por antonomasia, son peculiares y privados, porque están connotados de cierto pudor que hace que los disimulemos en el fondo de la maleta y los preservemos de miradas indiscretas. En segundo lugar, también incluimos entre los elementos definitorios de la identidad que comporta la maleta objetos que pueden tener un valor menos concreto y más simbólico en el marco del viaje, por ejemplo, los libros. Hallamos una ocurrencia significativa, desde esta perspectiva, en La parte inventada (2014), última novela de Rodrigo Fresán, cuya portada representa la imagen de Mr. Trip, un viajero-juguete que sostiene una maleta personalizada con los adhesivos de los lugares que ha visitado, y que emprende un nuevo viaje cada vez que se le vuelve a dar cuerda. En el capítulo final leemos que "la relación tamaño/carga del equipaje es tan engañosa y difícil de calcular a simple vista como la de los libros. Sobre todo cuando [...] la maleta está casi toda llena de libros por abrir, la mayoría de William Faulkner. Casi nada de ropa" (462-463). Los libros aquí personalizan el contenido de la maleta, mudan la forma estándar de su interior, puesto que son el resultado de una selección previa del viajero, que ha establecido, según su gusto y sus antojos, llevarse para "leer ahí arriba o aquí abajo [...]" aquello que "no se leyó en el espa- 
cio de costumbre, en la cama de siempre, en los sitios que se suele frecuentar" (463). Desde esta óptica, desde luego es ineludible la referencia a la Historia abreviada de la literatura portátil, de Enrique Vila-Matas.

En este sentido, es útil subrayar la relación estrecha que a menudo aparece en estas distintas ficciones entre escritura y viaje por medio justamente del recurso a la maleta; una articulación que conviene entender dentro de esta capacidad que tiene la valija de transportar el peso de la identidad singular de cada viajero. Varios son los relatos, ya no únicamente latinoamericanos, en los cuales la maleta, eventualmente extraviada, ocupa un lugar central de la historia, en cuanto objeto dotado de cierta humanidad que, por un lado, conduce a la génesis de la escritura y, por otro, produce incluso verdaderas epifanías. Refirámonos en particular al texto "La maleta de mi padre", conferencia pronunciada por el escritor turco Orhan Pamuk durante la entrega del Premio Nobel de Literatura, en 2006, que describe el valor que puede asumir un objeto como la maleta, en principio estándar e impersonal, según lo definimos al principio.

En el relato de Pamuk, todo lo que queda del padre muerto se encuentra contenido en una maleta que el escritor no logra abrir. Gira alrededor de ella, sin tocarla, la mira, la observa a pesar de que le resulta tan familiar aquella maleta pequeña de cuero negro que contiene manuscritos y cuadernos de apuntes. La maleta ya había caído entre sus manos dos años antes de la muerte del padre. Este se la había entregado diciéndole que cuando ya no fuera de este mundo, él, escritor, podría hacer una selección de aquellos textos y publicarlos. La vacilación de Pamuk en abrir la maleta se debe precisamente al miedo de encontrarse en la posición incómoda de tener que evaluar la calidad literaria de aquellos papeles, teniendo que entrar en el secreto de la personalidad del padre. La maleta ya no es aquí meramente un objeto-contenedor, sino que adquiere un valor simbólico elevado, que convierte un gesto tan simple como el de abrirla en un acto de proeza emotiva. En esta misma línea, es pertinente recordar otra maleta, la que contiene aquellos libros muy queridos de los cuales no es posible separarse a pesar de las restricciones del viaje. Verdadero topos, esta maleta es una figuración alegórica tanto de la literatura como de la "capacidad del hombre de crearse y recrearse" (Vázquez Paravano et al. 3) a partir de la memoria inmaterial que permite trasladar físicamente aquel "puro objeto". No obstante la aceleración generalizada del mundo global, la dimensión del pasado y del tiempo espeso permanece en creaciones que ponen la maleta en el centro de una experiencia poética, como en el caso del poemario El equipaje abierto de Felipe Benítez Reyes:

Todas nuestras maletas

Reflejan la ordenación desvanecida 


\author{
de un viaje \\ que siempre ha sucedido en el pasado. \\ Y las abrimos \\ con la perplejidad de quien se encuentra \\ una maleta absurda \\ en esa soledad de centinela \\ que parecen tener las playas en invierno. (16)
}

La maleta revela al individuo una wasteland, en la que este es el único testigo de un pasado que ya queda impreciso en la memoria. El riesgo al cual la maleta expone al ser humano no es externo, sino muy secreto, y, por eso mismo, genera duda, temor, alerta. Por lo tanto, el gesto banal de abrir la maleta implica aquí una voluntad de introspección y un compromiso interior que excluye al individuo del mundo para reconciliarlo con su pasado, en lugar de lanzarlo al mundo, según la función usual de la maleta en tanto "puro objeto".

\title{
La maleta de "puro objeto" a "casi-objeto"
}

Esta relación íntima entre el sujeto y el equipaje implica un estatuto particular para la maleta que se opone a su definición intuitiva inicial. A través de los ejemplos literarios examinados podemos constatar la adhesión de la literatura contemporánea a una tendencia actual de las ciencias humanas, en particular la sociología y la antropología, según Latour y Appadurai, tendencia que consiste en reconocer al objeto un estatuto nuevo, híbrido, que hace que dicho objeto sea considerado parte activa en la fabricación del cuerpo social. Esta reconfiguración de la objetividad, en cuanto propiedad de los objetos, limita el monopolio que las ciencias y tecnologías detentaban tradicionalmente en el estudio de los objetos, y hace que podamos analizarlos como medios de construcción y representación de las colectividades. Según esta óptica, la maleta puede legítimamente ser tratada como "objeto compacto", conforme a la apelación que Latour recupera de Stengers. El objeto es "compacto", porque comunica implicaciones identitarias, literarias, antropológicas y económicas que superan su materialidad inmediata.

Este cambio de estatuto de "puro objeto", "cosa en sî" a "casi-objeto" (Latour, Nous n'avons 73) emerge claramente en un pasaje de la novela Aeropuertos (Fuguet). Aquí la maleta, entre otros objetos, permite exponer la diversidad de las personas que diariamente circulan por los aeropuertos. Ella misma es expresión de la globalidad, y los múltiples volúmenes, colores, fisonomías que puede tomar corresponden a la gama extensa de los pasajeros que se mueven alrededor del planeta. Leemos en Fuguet: "Al menos una cincuentena de personas con todo tipo de male- 
tas, guitarras, esquís, cajas metálicas que al parecer contienen equipos de filmación. Hay pasajeros muy rubios y otros muy morenos y de todos los tipos físicos". La maleta forma parte de este paisaje global marcado por la pluralidad de individuos que comparten, según la antropología contemporánea, una misma condición y conciencia cosmopolita (Agier). Así, la maleta no solamente se ha vuelto un objeto indispensable, que siempre tiene que estar al alcance de la mano, sino que también es un objeto antropológico en la medida en que refleja las tendencias de la moda, la tecnología y los grandes cambios de sociedad. Pensemos en el nacimiento de los vuelos low cost que han dictado nuevas formas de viajar (Friedrich) y, por ende, nuevos formatos de maletas, o en las medidas de seguridad más o menos estrictas en vigor en todos los aeropuertos del mundo, que han modificado sensiblemente el tipo de objetos y materiales que podemos llevar en el equipaje.

La hibridez reconocida a los objetos de nuestro mundo hace entonces que la maleta, como muchos otros objetos globales, pueda ser tratada como acteurréseau, según la antropología simétrica de Latour, o sea como elemento que puede actuar y hasta modificar la red, a pesar de no ser humano. Para eso, remitimos, por ejemplo, a la manera en que está tratada la maleta en una publicidad difundida en 2011 por la empresa Samsonite sobre la historia ya centenaria de la marca de equipaje más conocida mundialmente. La propaganda (Samsonite) consiste en un recorrido diacrónico a lo largo de los cien años de vida de la marca, construido con imágenes de archivo que muestran cómo la maleta Samsonite ha ido adaptándose progresivamente a los grandes momentos de la historia humana reciente y a las mutaciones que estos cambios de época han introducido en el modo de pensar y de viajar de los individuos. La publicidad hace coincidir las innovaciones tecnológicas con la evolución de la historia, mientras la voz en off habla en plural, produciendo una confusión entre el "we", "nosotros", que se refiere a Samsonite, y el "we", "nosotros", que remite al género humano (Samsonite). El elemento sintomático que plantea este anuncio es más fundamentalmente la capacidad de adaptación de la maleta a las exigencias cambiantes del hombre; una capacidad tan grande que hace que justamente sea posible leer la historia a través de la historia de la valija, en un continuo cronológico y antropológico inescindible.

Volviendo a la literatura y al arte, Souvenirs, el libro-maleta de Michel Butor, así como la "maleta-escritorio" de Paul Morand o la caja-maleta de Marcel Duchamp citados por Vila-Matas (9) son tres representaciones de esta nueva ontología atribuida a uno de los objetos ineludibles del mundo global. Ontología que, más recientemente, aparece de manera muy explícita en las Maletas migrantes imaginadas por cincuentas artistas plásticos contemporáneos que han creado obras de arte a partir de maletas pensadas como "contenedor de los afectos", 
"espacio íntimo dentro del cual el migrante lleva consigo la memoria y los anhelos; su pasado, presente y futuro" (Vázquez Paravano et al. 3 ). ${ }^{3}$

Esta ontología reconocida a la maleta es utilizada incluso con fines comerciales por algunas compañías aéreas que construyen sus mensajes publicitarios refiriéndose a este trato distinto de la maleta, fuera de su función de "puro objeto". Es, por ejemplo, el caso de la compañía estadounidense Delta Airlines que, en una de sus recientes campañas, ha optado justamente por esta tendencia en provecho propio. El reclamo en cuestión se construye alrededor de dos figuras principales: una niña y una maleta-osa. En este sentido, la elección de una mirada infantil por parte de Delta no es en absoluto casual, por cuanto es propio de la infancia el hecho de tener una mirada animista que hace que se les atribuya un alma a los objetos y a los animales. La niña se entristece a la hora de entregar su equipaje, por tener que separarse de su maleta-osa, y vuelve a sonreír cuando la ve aparecer en la cinta del carrusel. La publicidad está construida alrededor de esta percepción emotiva y del vínculo psicológico entre la osa y la niña, que culmina en el encuentro final con la maleta. ${ }^{4}$ La compañía hace hincapié en esta situación de incertidumbre que implica el hecho de separarse de su equipaje para insistir en el valor que Delta atribuye al pasajero en términos de seguridad, de puntualidad y, sobre todo, de respeto hacia su equipaje, que es tratado igual que un individuo. De ahí la importancia de mostrar claramente los meandros del aeropuerto y los protocolos de seguridad que atraviesa la maleta-osa, tomando en cuenta sus sensaciones de temor y soledad, tanto dentro del escáner como bajo la lluvia, donde se encuentra con acompañantes desconocidos. Es evidente que la publicidad plantea aquí una verdadera individualización de la maleta, que ya no es un objeto que se mira, sino un objeto-que-mira y que, por lo tanto, desprende una fuerte carga simbólica y emotiva, definitivamente humana. ${ }^{5}$

En lo que concierne a la literatura, uno de los mejores ejemplos de esta ontología peculiar atribuida al equipaje se halla en el ya citado texto de la conferencia

3 También cabe citar en esta óptica la obra escultural y pictórica del español Eduardo Úrculo (1938-2003) alrededor de la figura del viajero nómada, circundado de maletas voluminosas que lo acompañan en sus múltiples desplazamientos por el mundo.

4 Sería interesante, a partir de este caso, analizar más detenidamente la manera en que ciertas problemáticas de género emergen claramente de esta publicidad y de muchas otras escenas sobre aviones y aeropuertos en el cine y la literatura actuales. Esta lectura de género nos ha sido sugerida por Moira Fradinger, a quien agradecemos aquí esa mirada pertinente sobre nuestro corpus. Llevaremos un análisis minucioso a partir de esta perspectiva de género en un libro en preparación sobre el imaginario aeronáutico en la narrativa contemporánea.

5 Una articulación similar niño-animal puede constatarse en la publicidad del servicio "Lost and Found" de la compañía holandesa KLM en el aeropuerto Schiphol de Ámsterdam. 
"Writing with Two Passports", que Andrés Neuman pronunció en 2014 en la Universidad de Oklahoma. Mientras observa su valija roja en la soledad y el anonimato de una habitación de hotel, Neuman concibe una verdadera fenomenología de la maleta en cuanto experiencia de percepción productiva y consciente. Dado que su contenido es el resultado de una selección minuciosa, la maleta responde a una disciplina de eliminación impuesta por el nomadismo actual y es al mismo tiempo el emblema de la condición de homelessness del escritor global contemporáneo que escribe entre dos pasaportes. Neuman vincula la imagen de la maleta con la de la lengua que un escritor lleva consigo al desplazarse por el mundo. La escritura es asi-

milada a este ejercicio de renuncia que es el arte de hacer maletas y eso, sobre todo, cuando la lengua en la cual se escribe no coincide con la lengua del lugar en el que se escribe o del lugar de nacimiento. Sentirse extranjero en su propia lengua, sentirse provisorio en otra lengua, es comparable a la sensación de vivir transportando una maleta de un lugar a otro, sin homeland, sin lugar de origen, ni destino final, en una forma de pura transición. Así como lleva su maleta, el escritor traslada la lengua en la que se escribe como si se tratara de un equipaje de mano. Esta poética, propia de muchos escritores actuales, es la que Neuman define, con una clara referencia a la maleta, como "poética de mano" (Neuman, "Poética de mano").

La maleta se vuelve así un objeto-símbolo del hombre contemporáneo, además de constituir un objeto para la escritura y de ser un motor para la creación artística y literaria. Si, como en el caso del personaje interpretado por George Clooney, la maleta sigue siendo un objeto del flujo, también reintroduce irremediablemente en ese mismo flujo la mano que la lleva, la del individuo. En este sentido, la maleta implica siempre un punto de vista particular que contradice el supuesto anonimato del flujo y permite, al contrario, analizarlo y modelarlo dentro de su movimiento, dado que el hombre con la maleta en la mano forma parte del flujo. La maleta es finalmente el soporte de una verdadera poética de la fluidez, que adapta modalidades de expresión humana a nuevas configuraciones del mundo. Al mantener el vínculo entre el hombre y el mundo, esta poética, y por ende la maleta, plantean claramente una manera de pensar la cultura dentro de la globalización y de pensar la cultura de la globalización.

\section{Obras citadas}

Agier, Michel. La condition cosmopolite: L'anthropologie à l'épreuve

du piège identitaire. Paris: La Différence, 2013. Impreso.

Appadurai, Arjun, comp. The Social Life of Things: Commodities in Cultural

Perspective. New York/Cambridge: Cambridge University Press, 1986. Impreso. 
Benítez Reyes, Felipe. El equipaje abierto (1992-1996).

Barcelona: Tusquets, 1996. Impreso.

Bradford, Timothy. Nomads with Samsonite. Buffalo,

New York: Blazevox, 2011. Impreso.

Butor, Michel. Souvenirs. Paris: Le Pont des Arts, 2013. Web. 9 de julio de 2015.

Caplan, Ralph. "Design for Travel(ers)". Bon Voyage: Design for Travel.

Comp. J. G. Links. New York: Cooper-Hewitt Museum, Smithsonian

Institution's National Museum of Design, 1986. 95-128. Impreso.

Delta Airlines. "Holiday Commercial: No Bag Left Behind. Keep

Climbing". 2014. Video web. 9 de julio de 2015.

Edwards, Justin D. y Graulund, Rune. Mobility at Large: Globalization, Textuality and

Innovative Travel Writing. Liverpool: Liverpool University Press, 2012. Impreso.

Faulconbridge, James. "The Executive". The Routledge Handbook of Mobilities.

Comps. Peter Adey et al. London: Routledge, 2014. 376-387. Impreso.

Fresán, Rodrigo. Historia argentina. Barcelona: Anagrama, 2003. Impreso.

Fresán, Rodrigo. La parte inventada. Barcelona: Random House, 2014. Impreso.

Friedrich, Alexandre. Easyjet. París: Allia, 2014. Impreso.

Fuguet, Alberto. Aeropuertos. Santiago de Chile: Alfaguara, 2010. Kindle.

Gamboa, Santiago. Los impostores. Barcelona: Seix Barral, 2002. Impreso.

Halfon, Eduardo. Monasterio. Barcelona: Libros del Asteroide, 2014. Impreso.

Kirn, Walter. Up in the Air. New York: Doubleday, 2001. Impreso.

KLM. "KLM Lost and Found Service" (1'43). 2014. Video web. 9 de julio de 2015.

Latour, Bruno. "Note sur certains objets chevelus". Nouvelle Revue

D'ethnopsychiatrie 27 (Grenoble, octubre de 1994): 21-36. Impreso.

Latour, Bruno. Nous n'avons jamais été modernes: Essai d'anthropologie

symétrique. París: La Découverte \& Syros, 1997. Impreso.

Latour, Bruno. Petite réflexion sur le culte moderne des dieux faitiches.

París: Les Empêcheurs de Penser en Rond, 1996. Impreso.

Lisle, Debbie. The Global Politics of Contemporary Travel Writing.

Cambridge: Cambridge University Press, 2006. Impreso.

Löfgren, Orvan. "Holidays". The Routledge Handbook of Mobilities. Comps.

Peter Adey et al. London: Routledge, 2014. 442-449. Impreso.

Muñoz Molina, Antonio. Ventanas de Manhattan. Barcelona: Seix Barral, 2004. Impreso.

Neuman, Andrés. Cómo viajar sin ver. Madrid: Alfaguara, 2010. Impreso.

Neuman, Andrés. "Poética de mano". Microrréplicas: blog de Andrew

Neuman 23 de mayo de 2012. Blog. 9 de julio de 2015.

Neuman, Andrés. "Writing with Two Passports: The ${ }_{2014}$ Puterbaugh Lecture".

World Literature Today 88.3/4 (Norman, mayo-agosto de 2014): 89-96. Impreso. 
Pamuk, Orhan. La maleta de mi padre. Trad. Rafael Carpintero.

Barcelona: Mondadori, 2007. Impreso.

Relatos salvajes. Dir. Damián Szifrón. Buenos Aires: Kramer \&

Sigman Films/Madrid: El Deseo, 2014. Película.

Roberson, Susan L. Defining Travel: Diverse Visions. Jackson:

University Press of Mississippi, 2001. Impreso.

Ruggerone, Luisa. "La valigia in viaggio: biografia culturale di un oggetto

'quasi' quotidiano". Studi di Sociologia 38.3 (2000): 289-310. Impreso.

Samsonite. "Samsonite Heritage Video" (1'43). 2011. Video web. 9 de julio de 2015.

Serrano Larraz, Miguel. Autopsia. Barcelona: Candaya, 2013. Impreso.

Tesich, Steve. Karoo. Trad. Javier Calvo. Barcelona: Seix Barral, 2013. Impreso.

Up in the Air. Dir. Jason Reitman. Los Ángeles: Paramount Pictures

y The Monte Cito Picture Company, 2009. Película.

Vázquez Paravano, Ignacio, Florencio Flavio y Claudia de la Garza, comps. Maletas migrantes, catálogo de la exposición presentada en el Museo Memoria y Tolerancia en la ciudad de México (7-22 octubre 2012). México D. F.: Ambulante, 2012. Web. 9 de julio de 2015.

Vila Matas, Enrique. Historia abreviada de la literatura portátil. Barcelona: Anagrama, 1985. Impreso.

Vuitton, Louis. A fourney Through Time: A Louis Vuitton Retrospective Exhibition. París: Louis Vuitton, 1983. Impreso. 